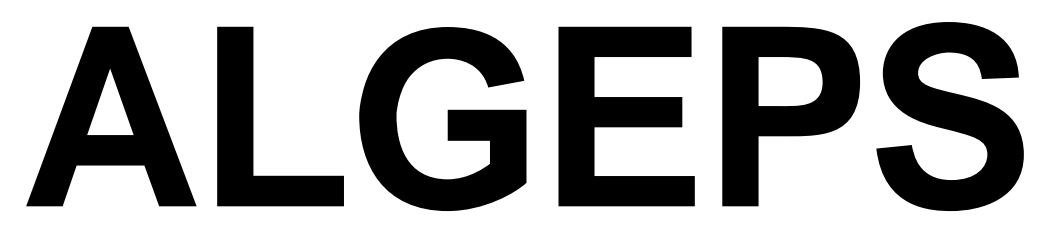

REVISTA DE GEOLOGIA, SÈRIE B no 637 - Juliol del 2013

\title{
RECORREGUT GEOLÒGIC I MINER PER LES COMARQUES DEL RIPOLLÈS I DE LA GARROTXA: DES DE SANT JOAN DE LES ABADESSES A LA VALL DE VIANYA, OLOT, CASTELLFOLLIT DE LA ROCA I A SANT JOAN DE LES FONTS
}

Josep M. Mata-Perelló i Joaquim Sanz Balagué

Aquest recorregut va ésser experimentat amb docents el dia 14 DE GENER DEL 2012 


\section{RECORREGUT GEOLÒGIC I MINER PER LES COMARQUES DEL RIPOLLÈS I DE LA GARROTXA: DES DE SANT JOAN DE LES ABADESSES A LA VALL DE VIANYA, OLOT, CASTELLFOLLIT DE LA ROCA I A SANT JOAN DE LES FONTS}

Per Josep M. MATA-PERELLÓ

\section{ADVERTIMENTS PREVIS}

Com en altres recorreguts de RECERCA GEOLÒGICA I MINERALÒGICA ..., si es disposa del temps suficient, poden efectuar-se passant per totes les parades i filloles. En cas contrari, recomanem prescindir de les anomenades PARADES - CONDICIONALS.

Cal dir també, que en aquest itinerari ens trobarem davant de tres trams de camis forestals en molt mal estat de conservació; per la qual cosa serà molt millor transitar a peu per ells. Això pot succeir en alguns dels trajectes d'aproximació a les aturades.

En qualsevol cas, cal tenir sempre una cura molt especial de respecte a la natura, al llarg de tot el recorregut; de l'itinerari.

\section{BREU INTRODUCCIÓ}

El recorregut del present itinerari, es desenvoluparà per uns indrets d'una estructura força complexa. Així, discorrerà per la zona de contacte entre el Sistema Pirinenc i la Depressió Geològica de l'abret; i més concretament, es desenvoluparà, pel que fa a la primera unitat, través del Mantell del Cadí; i pel que fa a la segona, a través de la zona de l'Avant-país plegat (prop de la Serralada Transversal Catalana). Aquest contacte, a través de les dues grans unitats geològiques, es realitzarà a través de 1’Encavalcament de Vallfogona.

I, també, aquest itinerari, a través dels seus darrers trams, discorrerà dintre de la Zona Volcànica de la Garrotxa, la qual es troba situada dintre de la Serralada Transversal Catalana.

Així, al llarg d'aquest trajecte, s'aniran veient els materials que composen les dues unitats geològiques acabades d'esmentar. I alhora, es veuran diverses mineralitzacions, incloses i distribuïdes entre els materials de les unitats esmentades anteriorment.

Per d'altra banda, aquest itinerari discorrerà quasi íntegrament per una sola comarca: per la de la Garrotxa (de la Regió de Girona). Tot i així, l'itinerari s śniciarà al Ripollès, a Sant Joan de les Abadesses, per a entrar ràpidament a la Garrotxa. Finalitzarà pels voltants de Sant Joan les Fonts, després de passar per Olot, la capital de la darrera comarca esmentada. 


\section{OBJECTIUS GENERALS} objectius:

A través d'aquest itinerari geològic-mineralògic, s'intentaran d'aconseguir els següents

1.- Observació al llarg del recorregut, de les estructures dels Pirineus Meridional; i en concret del Mantell del Cadí, que trobarem en alguns dels trams del recorregut, especialment entre Sant Joan de les Abadesses i els indrets septentrionals de la comarca de la Garrotxa, al Nord d'Olot.

2.- Observació i reconeixement dels materials cenozoics, que en aquests indrets formen part del Mantell del Cadí, i que es distribueixen entre les següents unitats litoestratigràfiques: Formació Armàncies (amb calcolutites noduloses grises i interpel-lacions carbonatades), Formació Campdevànol (amb nivells de guixos), Formació Vallfogona (amb turbidites, de gresos i calcolutites grises), Formació Banyoles (amb calcolutites grises i nivells bioclàstics), Formació Barcons (amb nivells de conglomerats, gresos i calcolutites grises) i Formació Bellmunt (amb conglomerats, gresos i calcolutites roges).

3,- Observació, a distància de les estructures de la Zona d'Apilaments Antiformes del Freser (del Sistema Pirinenc), que veurem a l'esquerra del recorregut, entre Sant Joan de les Abadesses i els voltants de Sant Pau de Segúries.

4.- Observació, a distància dels materials paleozoics (fonamentalment del Cambroordovicià al Permià), que constitueixen la Zona d'Apilaments Antiformes del Freser.

5.- Observació i estudi de les estructures de l'Avant-país plegat i de la Serralada Transversal Català, que trobarem entre la Vall de Bianya, Olot i el final del recorregut de l'itinerari a Sant Joan les Fonts.

6.- Observació de l'Encavalcament de Vallfogona, que travessarem prop de la ciutat d'Olot (al Nord de la mateixa), el qual posa en contacte els Pirineus Meridionals amb la zona de l’Avant-país plegat.

7.- Observació i reconeixement dels materials cenozoics, que formen part en aquests indrets de la zona de l'Avant-país plegat (i també de la Serralada Transversal Catalana), que es distribueixen entre les següents unitats litoestratigráfiques: Formació Armàncies, Formació Beuda (amb nivells de guixos blanc i grisosos), Formació Banyoles, Formació Coubet (amb conglomerats, gresos i calcàries), Formació Barcons, Formació Bellmunt, Formació Folgueroles (amb gresos i microconglomerats grisos), Unitat del Puigsacalm Superior (amb conglomerats, gresos i calcolutites grises) i Unitat Vidrà Inferior (amb gresos i calcolutites grises). Cal dir que algunes d'aquestes formacions litoestratigràfiques, també formen part del Mantell del Cadí (tal com hem comentat a l'apartat 2).

8.- Observació de la Zona volcànica de la Garrotxa (inclosa a la Serralada Transversal Catalana), de les seves estructures i dels seus materials. Així, es veuran les estructures volcàniques del Montsacopa, del Cruscat i del Santa Margarida; així com el dipòsits de la Cot, de Sant Joan de les Fonts i de Castellfollit de la Roca.

9.- Estudi de diverses explotacions dels materials volcànics, i de la seva restauració, com les efectuades al Cruscat. 
10. - Estudi de les alteracions produïdes sobre el Medi Natural, a partir de les explotacions mineres esmentades anteriorment. I si s'escau, de les restauracions dutes a terme sobre les mateixes.

11.- Observació dels indrets relacionats amb el Patrimoni Geològic i amb el Patrimoni Miner, que anem trobant al llarg del recorregut de l'itinerari.

\section{ANTECEDENTS}

Pel que fa al recorregut del present itinerari, existeixen diferents antecedents. En concret, farem esment dels nostres treballs: MATA-PERELLÓ (1996 i 2007). Tanmateix farem esment d'un recent treball nostre: MATA-PERELLÓ (2011), relatiu als indrets propers a Sant Joan de les Abadesses. També farem esment del treball de GASSIOT i RIERA (1981).

Pel que fa a les característiques generals de la geologia regional, farem esment de dos treballs: GUIMERÀ et altri (1992), i RIBA et altri (1976). I, pel que fa a la geologia de la zona per la qual discorre el recorregut de l'itinerari, farem esment dels següents treballs: ARAÑA et altri (1983), ITGME (1994a i 1994b), MALLARACH (1968) MALLARACH i RIERA (1981).

També, pel que fa a les mineralitzacions situades a les comarques per les quals discorre l'itinerari, farem esment d'un treball nostre; concretament de: MATA-PERELLÓ (1991).

Tots aquests treballs figuren relacionats, per ordre alfabètic a l'apartat dedicat a la BIBLIOGRAFIA.

\section{RECORREGUT DE L'ITINERARI}

Com ja s'ha dit, l'itinerari s'iniciarà a la comarca del Ripollès, concretament prop de la població de Sant Joan de les Abadesses, per a finalitzar a la comarca de la Garrotxa, per les immediacions de Sant Joan de les Fonts.

Així, després d'iniciar-se el recorregut, ja es farà la primera aturada molt prop de Sant Joan de les Abadesses. Després, seguint la carretera $\mathrm{N}$ - 260, el recorregut es dirigirà cap a la Garrotxa, cap a la Vall de Bianya, des d'on s'anirà cap a Olot. En aquest trajecte es farà una nova aturada; i en arribar a Olot, se'n faran dues més: una al Volcà Montsacopa, i una altra a la Casa dels Volcans.

Des d'Olot es farà una fillola per tal d'anar cap als voltants de Santa Pau. En aquesta fillola, s'anirà a veure els cons volcànics del Cruscat i del Santa Margarida. També es veuran els lapil-lis de la Cot. En aquest tram es faran tres noves parades.

Després de fer la fillola, es retornarà a Olot, per tal d'anar després, tot seguint la carretera nacional N-260, cap a Castellfollit de la Roca, on es faran dues noves aturades. I, finalment, es retornarà enrere, fins a trobar el trencall que es dirigeix cap al poble de Sant Joan de les Fonts, on es farà la darrera aturada del recorregut de l'itinerari. Així, aquest finalitzarà en aquest indret de la comarca de la Garrotxa. 


\section{DESCRIPCIÓ DE L'ITINERARI}

Com ja es habitual, aquest itinerari s'estructurarà en una sèrie d'estacions (parades o aturades). En cada una d'aquestes parades es faran descripcions geològiques o mineralògiques, segons s'escaigui. En cada cas s'indicarà el número del mapa topogràfic a escala 1:50.000 on es troba l'indret.

En aquest cas, el recorregut de l'itinerari passarà per part dels dos següents fulls: 256 (o full de Ripoll) i 257 (dit d’Olot). En ambdós casos, aquests fulls són del IGC (Instituto de Geografia y de Cartografia).

Així doncs, la descripció de les diferents aturades que constitueixen el recorregut de l'itinerari, és la següent:

PARADA 1. LA GUIXERA, (terme municipal de Sant Joan de les Abadesses, comarca del Ripollès). (Full 256).

El recorregut 1'haurem iniciat al bell mig de Sant Joan de les Abadesses. Tot seguit, cal agafar la carretera N-260, en sentit oriental. A poca distància del poble, cal seguir per un camí que es dirigeix cap al Sud, i que condueix cap al paratge de la guixera. En aquest indret, situat a uns $3 \mathrm{Km}$ de la població, és on ens cal fer la present aturada.

En aquest recorregut, s'aniran tallant els materials cenozoics que formen part dels relleus pirinencs del Mantell del Cadí. Fonamentalment es tracta de trams de calcolutites grisenques, trams de turbidites també grisenques. Tots aquests materials son els que es troben pels voltants de Sant Joan de les Abadesses.

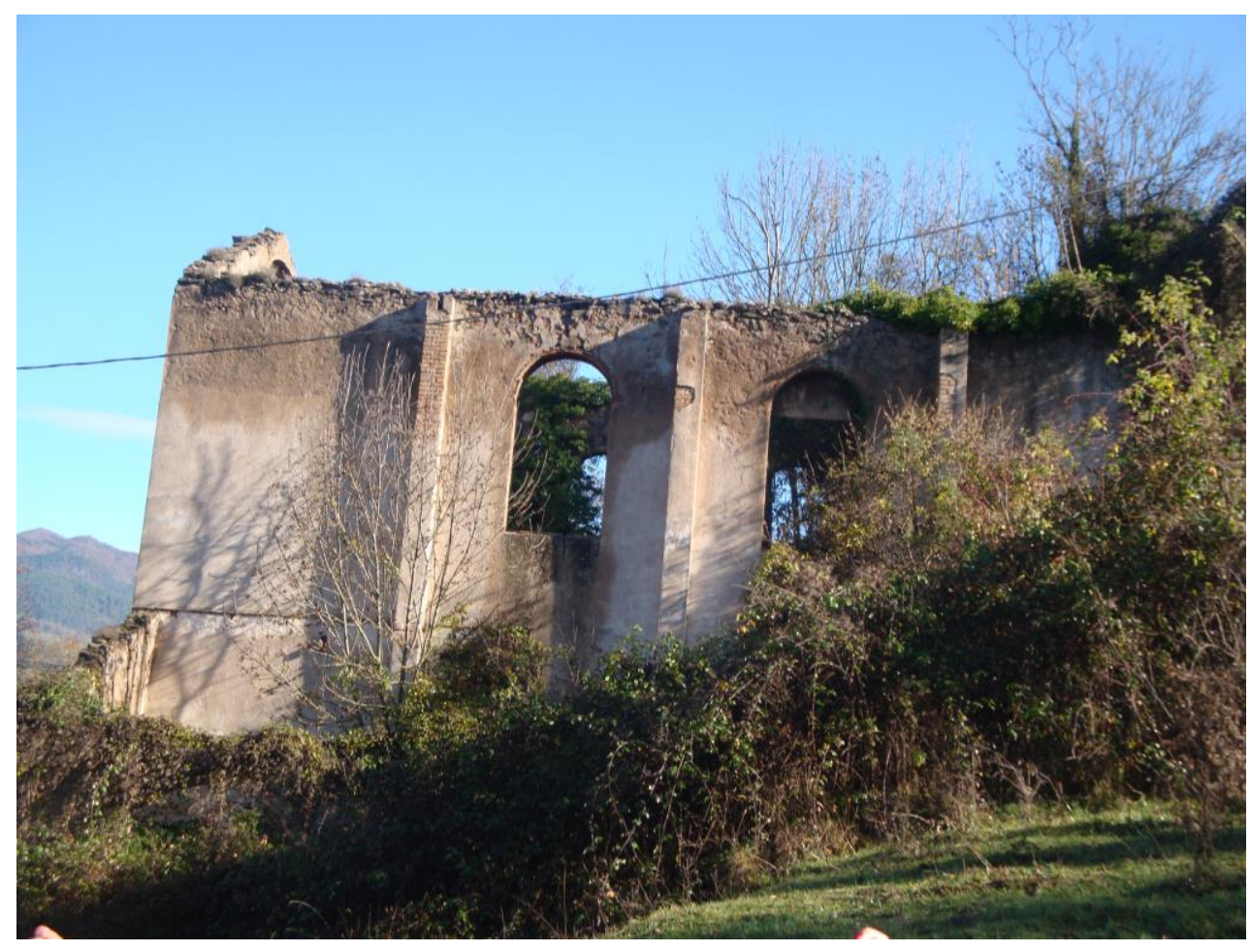

FOTOGRAFÍA 1. Un aspecte de l’antiga guixera 
Aquests materials són també els que apareixen a l'indret de l'aturada, on afloren uns nivells de guixos, els quals pertanyen a la Formació Campdevànol. En efecte, aquí hi ha un aflorament dels nivells de guixos, els quals pertanyen a la. Aquests han estat explotats, per tal de dedicar-los a una antiga guixera. FOTOGRAFIA 1.

Per d'altra banda, al costat de la guixera anterior, n'havia una altra molt més antiga, un interessant Forn de Guix (FOTOGRAFIA 2). Aquest, forma part del Patrimoni Miner de la comarca de la Garrotxa.

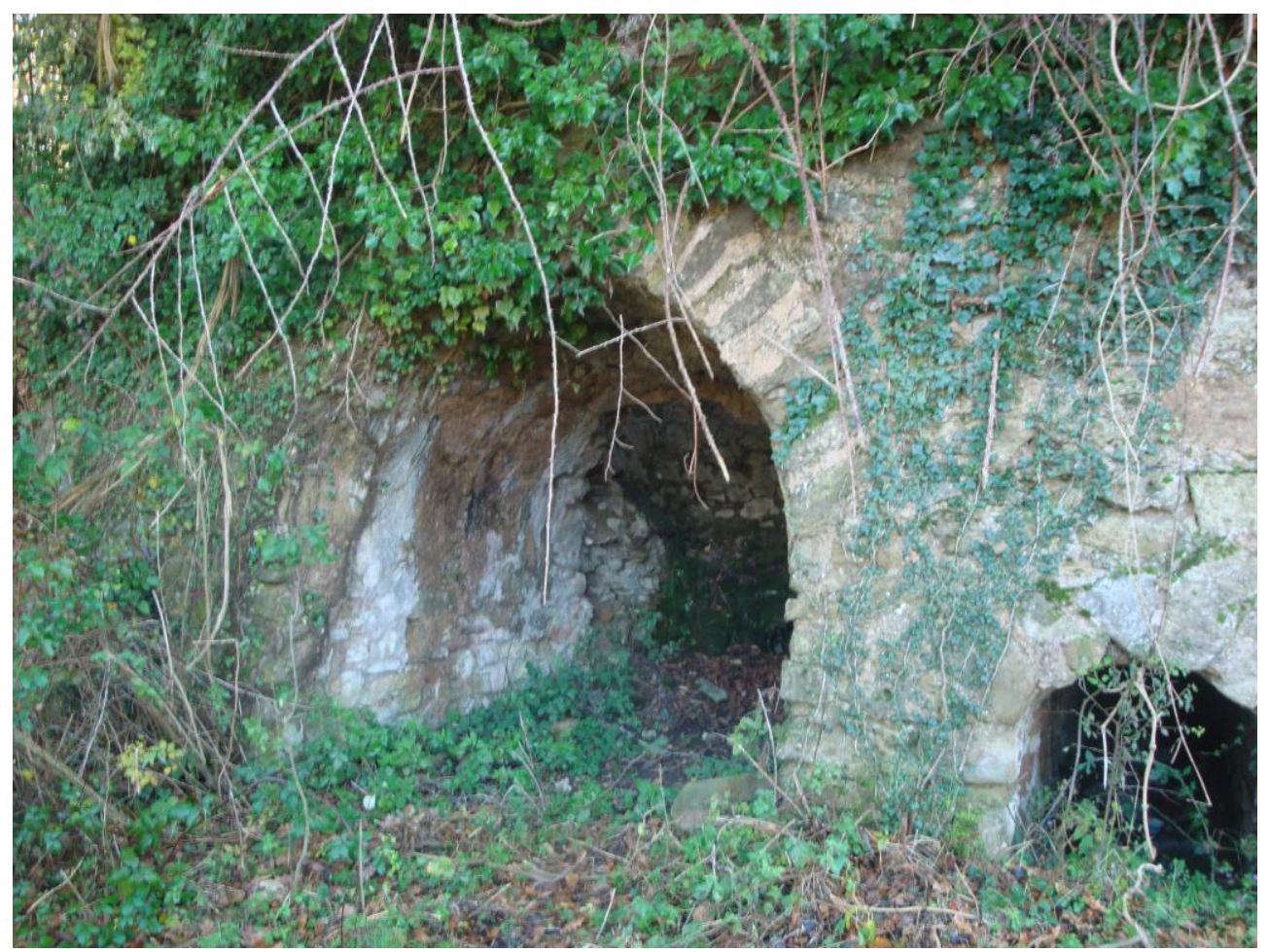

FOTOGRAFÍA 2. Un aspecte del Forn de Guix

PARADA 2. CARRETERA N - 260, DE SANT JOAN DE LES ABADESSES A OLOT, CRUÏLLA DEL TRENCAL A SANT PERE DESPUIG, (Sant Andreu de Sucarrats, terme municipal de la Vall-de-Bianya, comarca de la Garrotxa). (Full 256).

Després de realitzar la parada anterior, cal continuar per la carretera N-260, tot anant cap a Olot, Després de passar el Túnel de Capsacosta, ens caldrà arribar a la cruïlla amb la carretera que es dirigeix cap a Sant Pere Despuig, poc abans de sobrepassar el poblet de Sant Andreu Sucarrats, caldrà fer la present aturada. Així, des de l'iniciï del recorregut, haurem fet un trajecte proper als $10 \mathrm{Km}$.

En aquest indret on ara som, apareixen uns nivells rogencs constituïts per nivells de conglomerats, gresos i calcolutites rogenques, les quals pertanyen a la Formació Bellmunt. Precisament aquests nivells són els que formen els indrets pels quals discorre el Túnel de Capsacosta (situats més amunt d'on ara som); i també són els que afloren prop de l'indret on cal efectuar la present aturada. 
Per d'altra banda, en el recorregut des del túnel, es travessa tot un conjunt de plecs, d'anticlinals i de sinclinals, que presenten uns arrumbaments de direcció generalitzada de E-W.

\section{PARADA 3. CON VOLCÀNIC DEL MONTSACOPA, (terme municipal d’Olot, comarca de la Garrotxa). (Full 256).}

Des de la parada anterior, cal continuar cap a Olot per la carretera nacional N-260 (antiga carretera comarcal C-153). En arribar a la Canya, cal dirigir-se cap al Sud, per tal d'arribar fins a la propera població d'Olot. En arribar-hi, cal pujar al cim del con del Montsacopa, pel camí que surt pel darrera del Cementiri, on hi ha unes graderes. Així, des de la parada anterior, caldrà efectuar un recorregut aproximat d'uns $9 \mathrm{Km}$.

En tot aquest recorregut, es van troben diversos materials cenozoics de 1'Eocè, els quals pertanyen en la seva major part a la Formació Bellmunt, la qual es troba constituïda per nivells de conglomerats, gresos i calcolutites rogenques. Per d'altra banda, entre la Canya i Olot, es tallen diversos nivells que pertanyen a la Formació Bracons (amb conglomerats, gresos i calcolutites grisenques), a la Formació Banyoles (amb calcolutites grises que contenen nivells bioclàstics), a la Formació Beuda (amb nivells de guixos) i a la Formació Vallfogona (amb turbidites).

Prop, també es troben afloraments que pertanyen a la Formació Armàncies (amb nivells de calcolutites grises, d'aspecte nodulós, les quals contenen freqüents interpel-lacions de carbonatades), i també a la Formació Coubet (amb conglomerats, gresos i calcàries). Més cap al $\mathrm{NE}$, es troben uns nivells més moderns, de la Unitat del Puigsacalm Inferior (amb conglomerats, gresos, i amb calcolutites grises), i de la Unitat Vidrà Inferior (amb gresos i calcolutites grises). Molt sovint, tots els materials anteriors, es troben coberts per terrenys quaternaris.

Poc abans d'arribar a Olot, es travessa 1'Encavalcament de Vallfogona, el qual posa en contacte tots els materials anteriors (els quals constitueixen el Mantell del Cadí, del Sistema Pirinenc), amb els nivells eocènics que formen part de 1'Avant-país plegat (de la Depressió Geològica de l'Ebre). Cal dir que aquesta darrera es troba representada pels nivells de la Formació Bellmunt.

Pel que fa al Volcà del Montsacopa, cal dir que es tracta d'un cràter senzill, centrat i simètric, trobant-se molt ben conservat. Des del seu cim es pot veure el cràter compost del Volca de la Garrinada, el qual es troba al NE de l'indret on som. En aquest cas, el volcà es troba composat per tres cràters, alineats segons una falla NNW-SSE. La seva lava és bàsica, basàltica, i el dinamisme de les seves explosions va ésser de tipus strombolià.

Per d'altra banda, des d'aquest indret es pot veure el Volcà de les Biseroques, situat al SE de l'indret on ara som. I. també, mirant cap al SSW, dintre de la ciutat d'Olot, es pot veure el Volcà Montolivet.

I, tanmateix, es pot veure com els volcans de la Garrinada, del Montsacopa i del Montolivet, es troben alineats, tot seguint una fractura de direcció NE-SW. 
PARADA 4. LA CASA DELS VOLCANS, (terme municipal d'Olot, comarca de la Garrotxa). (Full 257).

Des de la parada anterior, cal retrocedir fins als carrers d'Olot, per tal d'anar cap a la Casa dels Volcans, on s'efectuarà la present aturada. Així, haurem recorregut uns $2 \mathrm{Km}$ més, aproximadament.

En aquest indret, hi ha una interessantíssima i didàctica explicació gràfica, de les característiques geològiques de la Zona Volcànica de la Garrotxa. Cal visitar-la, per tal de tenir una idea, ben aproximada de les peculiaritats de la zona (en general), i dels diferents volcans (en particular).

PARADA 5. CAN XELL, (Sant Miquel de Sa Cot, terme municipal de Santa Pau, comarca de la Garrotxa). (Full 295).

Després de la parada anterior, cal sortir d'Olot, per la carretera que es dirigeix cap a Banyoles i cap a Santa Pau. Per aquesta carretera, en uns 5'5Km s'arriba a Can Xell, i al trencall que condueix cap a Sant Miquel de Sa Cot. En aquest indret de la carretera, cal fer la present aturada.

En tot el recorregut es van tallant diversos materials quaternaris, d'origen volcànic, els quals cobreixen els terrenys cenozoics de l'Eocè, que pertanyen a la zona de l'Avant-país plegat, i també a la Serralada Transversal Catalana.

En aquest indret, hi ha un interessant aflorament de lapil-li, situat a la bora de la carretera, entre el qual es troben abundants bombes volcàniques.

PARADA 6. VOLCÀ DE SANTA MARGARIDA, (terme municipal de Santa Pau, comarca de la Garrotxa). (Full 295).

Des de la parada anterior, cal continuar per la carretera, fins a trobar el trencall que s'adreça per la dreta cap al Volcà de Santa Margarida, tot passant pel Coll de Can Casselles. Aquest trencall es troba a una mica més de $0{ }^{\prime} 5 \mathrm{Km}$ de la parada anterior; i, després, en $1 \mathrm{Km}$ més s'arriba fins al cim del volcà.

Des d'ell cim del cràter del volcà, pel seu marge septentrional, es pot gaudir de la seva morfologia. Es tracta d'un volcà centrat, i aparentment senzill. La seva lava és bàsica, i les seves erupcions van tenir episodis estrombolians i també de caràcter explosiu.

Des d'aquest indret, hi ha la possibilitat d'anar cap al Volca Roca Negra, situat a menys de 1'5Km de l'indret on som ara, tot anant cap a l'Est, apropant-nos cap a la població de Santa Pau. Aquest volcà te característiques molt similars a les del que acabem de veure.

Per d'altra banda, en aquest volcà (PARADA 6-BIS), i en especial a les seves graderes, hi ha la possibilitat de trobar bones mostres d'AUGITA i de SANIDINA. 
PARADA 7. VOLCÀ DEL CROSCAT, (terme municipal de Santa Pau, comarca de la Garrotxa). (Full 295).

Després de la parada anterior, cal retornar cap a la carretera local que enllaça Olot amb Banyoles, i cal arribar fins al Collet de Mont, des d'on parteix el camí que condueix cap al Volcà del Croscat, Així, des de la parada anterior, i fins a l'esmentat volcà caldrà fer un recorregut de menys de $2 \mathrm{Km}$.

Tot el recorregut, com l'efectuat entre les dues parades anteriors, s'efectua per amplis afloraments de materials quaternaris d'origen volcànic, els quals cobreixen als terrenys neògens de 1'Eocè.

En arribar al volcà, pot gaudir-se de l'observació d'un interessant cràter asimètric, en forma de ferradura. Es tracta d'un volcà d'erupcions estrombolianes, que ha patit durant anys una clara espoliació, produïda per l'explotació dels seus materials. Actualment s'ha dut a terme un valuós procés de restauració.

Per d'altra banda, cap a llevant del Volcà del Croscat, es pot veure el con del Volcà de Puigsafont.

PARADA 8. CINGLERA DE CASTELLFOLLIT DE LA ROCA, (terme de Castellfollit de la Roca, comarca de la Garrotxa). (Full 257).

Després d'efectuar la parada anterior, cal retornar a la carretera local que enllaça Olot amb Banyoles, per tal de tornar a la primera ciutat. Després, des d'Olot, cal continuar per la carretera nacional N-260, per tal d'anar cap a Castellfollit de la Roca. En arribar-hi, cal passarla, per tal de fer la parada cap els voltants de Can Peric, després de sobrepassar el trencall que duu a Oix. Així, des de la parada anterior, ens caldrà fer un recorregut de prop de $15 \mathrm{Km}$.

La major part d'aquest recorregut, cal efectuar-lo entre diferents materials quaternaris d'origen volcànic, els quals cobreixen alls terrenys eocènics de la Formació Bellmunt, i de la Formació Coubet (que aflora prop de l'indret on s'efectua la present aturada).

Des d'aquest indret, és possible de veure una interessant superposició de colades basàltiques, sobre les que es troba situat el poble de Castellfollit de la Roca.

També hi ha la possibilitat d'entrar al poble, i de recórrer-lo fins a l'extrem del cingle que formen les colades basàltiques. En aquest cas, l'observació es realitzaria des de dalt.

\section{PARADA 9. CINGLERA DE SANT JOAN DE LES FONTS, (terme de Sant Joan de les Fonts, comarca de la Garrotxa). (Full 257).}

Des de la parada anterior, cal retornar per la carretera N-260, fins a trobar el trencall que condueix cap a Sant Joan de les Fonts. En arribar al poble, cal anar fins a l'església nova de Sant Joan, situada al costat del pont sobre el Riu Fluvià. I tot seguit, cal agafar un camí que condueix cap a unes antigues pedreres. Així, des de la parada anterior, ens caldrà efectuar un recorregut proper als 5-6Km. 
El recorregut s'efectua per entre afloraments quaternaris, d'origen volcànic, els quals cobreixen als terrenys terciaris de la Formació Coubet i de la Formació Bellmunt (que són els que es troben en aquest indret de la present parada). En aquest indret hi ha una interessant superposició de colades basàltiques, similar a les de la parada anterior.

\section{AQUÍ FINALITZA EL RECORREGUT DEL PRESENT ITINERARI}

\section{BIBLIOGRAFIA}

ARAÑA, S. et altri (1983).- El volcanismo neógeno-cuaternario de Catalunya: caracteres estructurales, petrográficos y geodinámicos. Acta Geológica Hispánica, 18 (1), pp. 1-17, Barcelona.

GASSIOT, X. i RIERA, M. (1981).- Itinerari per la Zona Volcànica de Catalunya. Pub. ICE$U A B, 36$ pàgines. Barcelona.

GUIMERÀ, J. et altri (1992).- Geologia (II), Història Natural dels Països Catalans, Vol. 2, 547 pag. Enciclopèdia catalana, S.A., Barcelona.

IGME (1994a).- Mapa Geológico de España a escala 1:50.000, Segunda série, Primera edición. Hoja y memória $\mathrm{n}^{\mathrm{o}} 256$ (Ripoll). Ins. Geominero y Tecnológico de España. Ministerio de Indústria y Energia. Madrid.

IGME (1994b).- Mapa Geológico de España a escala 1:50.000, Segunda série, Primera edición. Hoja y memória $\mathrm{n}^{\mathrm{o}} 257$ (Olot). Ins. Geominero y Tecnológico de España. Ministerio de Indústria y Energia. Madrid.

MALLARACH, J. M. (1968).- Carta Geològica de la Regió Volcànica d’Olot. Edit. Ajuntament d'Olot. Olot.

MALLARACH, J.M. i RIERA, M, (1981).- Els volcans olotins i el seu paisatge. Edit. Serpa. Barcelona.

MATA-PERELLÓ, J.M. (1991).- Els Minerals de Catalunya. Arxius de la Secció de Ciències, t. XCIII. Institut d'Estudis Catalans. Barcelona.

MATA-PERELLÓ, J.M. (1996).- Apunts per a un itinerari geològic - mineralògic per les comarques del Ripollès i de la Garrotxa: des de Campdevànol a Santa Pau, i a Sant Joan de les Fonts. Inèdit. 10 pàgines. Manresa

MATA-PERELLÓ, J.M. (2007).- Recorregut geològic i miner per la comarca de la Garrotxa: des de la Vall de Vianya i Olot cap a Castellfollit de la Roca i Sant Joan de les Fonts. Inèdit. 8 pàgines. Manresa 
RIBA ARDERIU, O. Et altri. (1976).- Geografia Física dels Països Catalans. Edit Ketres. Barcelona. 